\title{
Review Article \\ Clostridium difficile Infections: A Global Overview of Drug Sensitivity and Resistance Mechanisms
}

\author{
Saeed S. Banawas iD \\ Department of Medical Laboratory Sciences, College of Applied Medical Sciences, Majmaah University, Majmaah 11952, Saudi Arabia \\ Correspondence should be addressed to Saeed S. Banawas; s.banawas@mu.edu.sa
}

Received 24 December 2017; Accepted 28 January 2018; Published 21 February 2018

Academic Editor: Hon W. Koon

Copyright (C) 2018 Saeed S. Banawas. This is an open access article distributed under the Creative Commons Attribution License, which permits unrestricted use, distribution, and reproduction in any medium, provided the original work is properly cited.

\begin{abstract}
Clostridium difficile (C. difficile) is the most prevalent causative pathogen of healthcare-associated diarrhea. Notably, over the past 10 years, the number of Clostridium difficile outbreaks has increased with the rate of morbidity and mortality. The occurrence and spread of $C$. difficile strains that are resistant to multiple antimicrobial drugs complicate prevention as well as potential treatment options. Most $C$. difficile isolates are still susceptible to metronidazole and vancomycin. Incidences of $C$. difficile resistance to other antimicrobial drugs have also been reported. Most of the antibiotics correlated with C. difficile infection (CDI), such as ampicillin, amoxicillin, cephalosporins, clindamycin, and fluoroquinolones, continue to be associated with the highest risk for CDI. Still, the detailed mechanism of resistance to metronidazole or vancomycin is not clear. Alternation in the target sites of the antibiotics is the main mechanism of erythromycin, fluoroquinolone, and rifamycin resistance in C. difficile. In this review, different antimicrobial agents are discussed and $C$. difficile resistance patterns and their mechanism of survival are summarized.
\end{abstract}

\section{Introduction}

Clostridium difficile is a Gram-positive, anaerobic, sporeforming bacterium that is the most important causative pathogen of hospital-acquired diarrhea. Approximately 25\% to $33 \%$ of antibiotic-associated diarrhea and $90 \%$ of pseudomembranous enteritis are caused by CDI [1]. According to the Centers for Diseases Control and Prevention (CDC), in the United States, CDI is responsible for more than 400,000 cases and 29,000 deaths each year and approximately more than $\$ 1$ billion in additional medical budgetary costs $[2$, 3]. Thus, CDI is projected to become the most common healthcare-associated infection and hospital-acquired intestinal infection in the United States, Europe, and worldwide [4]. The clinical symptoms of CDI range from mild to severe diarrhea, which can lead to fulminant colitis, toxic megacolon, bowel perforation, sepsis, and ultimately death [5]. Although guidelines pertaining to the awareness, diagnosis, and treatment of CDI are available, the rate of CDI continues to increase in Europe and the United States [6].

The molecular study of the epidemiology of CDI has proved that a significant increasing number of outbreaks are caused by strains ribotype (RT) 027 and 078 [7]. In recent years, strain RT 027 has become the most prominent hypervirulent type that is responsible for severe infections and increasing mortality worldwide [8-13]. RT 078, another highly virulent strain, is found in European countries such as the Netherlands; causes infections in humans, particularly in the hospital and communities; and causes infections in animals [14-18].

CDI begins with an unusual exposure of the normal flora of the intestinal microbiota to antibiotics. This action results in a disruption of the normal intestinal microflora that allows for multiplication of $C$. difficile to cause disease [19]. Antibiotic resistance plays a crucial role in spreading CDI among hospitalized patients, particularly the elderly. Moreover, antibiotic resistance affects healthy people who have not been hospitalized or have not been submitted to antibiotic treatment and even pregnant women [20, 21].

In recent years, an increase in CDI has been reported in different countries. China, Sweden, and several other countries have reported a CDI incidence rate of $\sim 17.1$ cases $/ 10000$ admitted to a hospital [22]. CDI causes up to $30.7 \%$ of hospital infections and diarrhea cases. Additionally, RT 027 isolates are more common in the United States, Canada, 
and Poland [22-25]. The most important risk factor for CDI is broad-spectrum antimicrobial drugs that cause an imbalance of the intestinal microflora [26]. Several antimicrobial drugs such as erythromycin, penicillin, clindamycin, and fluoroquinolones cause CDI to spread more widely in and out of the hospital and increase the resistance of the epidemic strains of $C$. difficile to those drugs $[27,28]$. Strain 027 is the most frequently observed drug-resistant RT strain and shows a statistically high incidence in Europe and the United States. Several countries have reported the resistance of strain 027 to moxifloxacin and, more recently, to metronidazole and vancomycin [23, 24, 28-35]. Consequently, this article discusses the general antibacterial drugs used to treat CDI, the CDI strains most resistant to drugs, and the strains' mechanism of resistance.

\section{C. difficile Resistance to Antimicrobial Agents in Different Countries and Regions}

The wide use of antibiotic in different countries with different treatments area causes a varying degree of drug resistance. In $C$. difficile, although all isolates are usually susceptible to metronidazole and vancomycin, resistance to other antimicrobials varies widely from one country to another (Table 1). Several studies have found that $C$. difficile is resistant to different antimicrobial agents in different countries (Table 1). Interestingly, the clinical isolates of $C$. difficile are still significantly sensitive to metronidazole and vancomycin, but there are reports of decreased susceptibility to metronidazole [24, 36-38]. Most of the antibiotics correlated with CDI, such as ampicillin, amoxicillin, cephalosporins, clindamycin, and fluoroquinolones, continue to be associated with the highest risk for CDI [27, 28]. The recommended treatment for primary and recurrent CDI involves the use of antibiotics with activities against $C$. difficile, including metronidazole, vancomycin, and fidaxomicin $[27,28]$. Studies report that more than 30 hospitals around the United State have found the rate of resistance of $C$. difficile to clindamycin in around $36 \%$ (Table 1) [29]. However, the rate of resistance is higher in European and Asian countries. The resistance rates of $C$. difficile to clindamycin in Spain, Poland, and New Zealand are approximately $74 \%, 65 \%$, and $61 \%$, respectively (Table 1 ) [39-41], whereas the rates of resistance of $C$. difficile to clindamycin in China, Japan, Korea, and Iran are approximately $73.5 \%, 87.7 \%$, 81\%, and 89.3\%, respectively (Table 1) [42-44]. C. difficile has developed a high resistance to another antimicrobial drug, moxifloxacin. In the United States and Canada, the rates of resistance to moxifloxacin are approximately $36 \%$ and $83 \%$, respectively (Table 1) $[29,45]$. A recent study in Germany reported that the rate of resistance to moxifloxacin can be as high as $68 \%$ (Table 1) [30]. Spain's resistance rate to moxifloxacin is $43 \%$, whereas Poland reported a resistance rate of nearly $100 \%$ (Table 1) $[24,40]$. Recent studies have found that in Brazil and Israel the resistance rates against moxifloxacin are approximately $8 \%$ and $4.76 \%$, respectively (Table 1 ) $[46,47]$.

The epidemic strains of $C$. difficile are more resistant to antibacterial drugs than are the nonepidemic strains. A study reported that, among 508 strains of $C$. difficile, PCR ribotype found that RT 027 was the most common, accounting for $28.1 \%$ of the isolates (143/508) [29]. The rates of resistance of $C$. difficile to clindamycin and moxifloxacin are $\sim 50.3 \%$ and $\sim 92.3 \%$, respectively [29]. Approximately $39.1 \%$ of the 027 strains have a lower susceptibility to vancomycin (the Minimum Inhibitory Concentration $\left(\mathrm{MIC}_{90}\right) 4 \mu \mathrm{g} / \mathrm{ml}$ ) [29]. Note that MIC results are based on Clinical and Laboratory Standard Institute (CLSI) document M11-A8 [29, 48, 49]. Another study confirms that the resistance rates of epidemic strain 027 to clindamycin, moxifloxacin, and erythromycin are higher than those of non-027 strains [33, 50]. In Asia, the RT 027 strain is rare, but the Korean epidemic strains RT 018 and 017 are resistant to clindamycin and moxifloxacin, significantly more so than nonepidemic strains $[51,52]$.

\section{Resistance Mechanism of $\boldsymbol{C}$. difficile to Most Commonly Used Drugs Recommended for CDI Treatment}

3.1. Metronidazole. Metronidazole is a nitroaromatic drug that requires reduction of the 5-nitro group of its imidazole ring to become cytotoxic to bacterial cells [56]. Metronidazole is the first-choice antimicrobial drug for treating mild to moderate CDI [57]. Although the resistance rate of C. difficile strains to metronidazole is very low (Table 1), several studies have reported treatment failure after an antibiotic course of metronidazole $[57,58]$. Moreover, the majority of clinical C. difficile isolates are still highly sensitive to metronidazole in vitro [59]. Recent studies have found that in Israel the rate of resistance of $C$. difficile against metronidazole is approximately $20.25 \%$ (Table 1) [46].

Furthermore, $12 \%$ of clinical isolates showed a heterogeneous resistance to metronidazole in 2008 [60] and were correlated with clinical failure. Approximately $25 \%$ of $C$. difficile epidemic 001 strains showed decreased sensitivity to metronidazole after a minimum inhibitory concentration (MIC 4 to $8 \mu \mathrm{g} / \mathrm{ml}$ ) was given [61]. In China, 18 isolates from Shanghai diarrhea patients with $C$. difficile were heterogeneously resistant to metronidazole [36]. In fact, most countries' criteria for in vitro drug susceptibility MIC results are based on the American Clinical and Laboratory Standards Association (CLSI) standards [48]. C. difficile can be classified as resistance to metronidazole if the MIC $\geq 32 \mu \mathrm{g} / \mathrm{ml}$, but the breakpoint for reduced susceptibly is based on serum treatment concentration rather than intestine treatment concentration [48]. In contrast, the European Society for Clinical Microbiology and Infection (ESCMID) guideline for resistance of $C$. difficile to metronidazole is mainly based on activity in the intestine. Since 2012, the reduction point has been $>2 \mu \mathrm{g} / \mathrm{ml}$ for drug resistance $[57,62,63]$. Therefore, the European Antimicrobial Susceptibility Test Committee (EUCAST) standards for detecting metronidazole resistance in C. difficile are significantly higher than those reported in the current literature.

EUCAST and CLSI guidelines are the most popular breakpoint guidelines used in antimicrobial susceptibility testing worldwide. However, there are some significant 


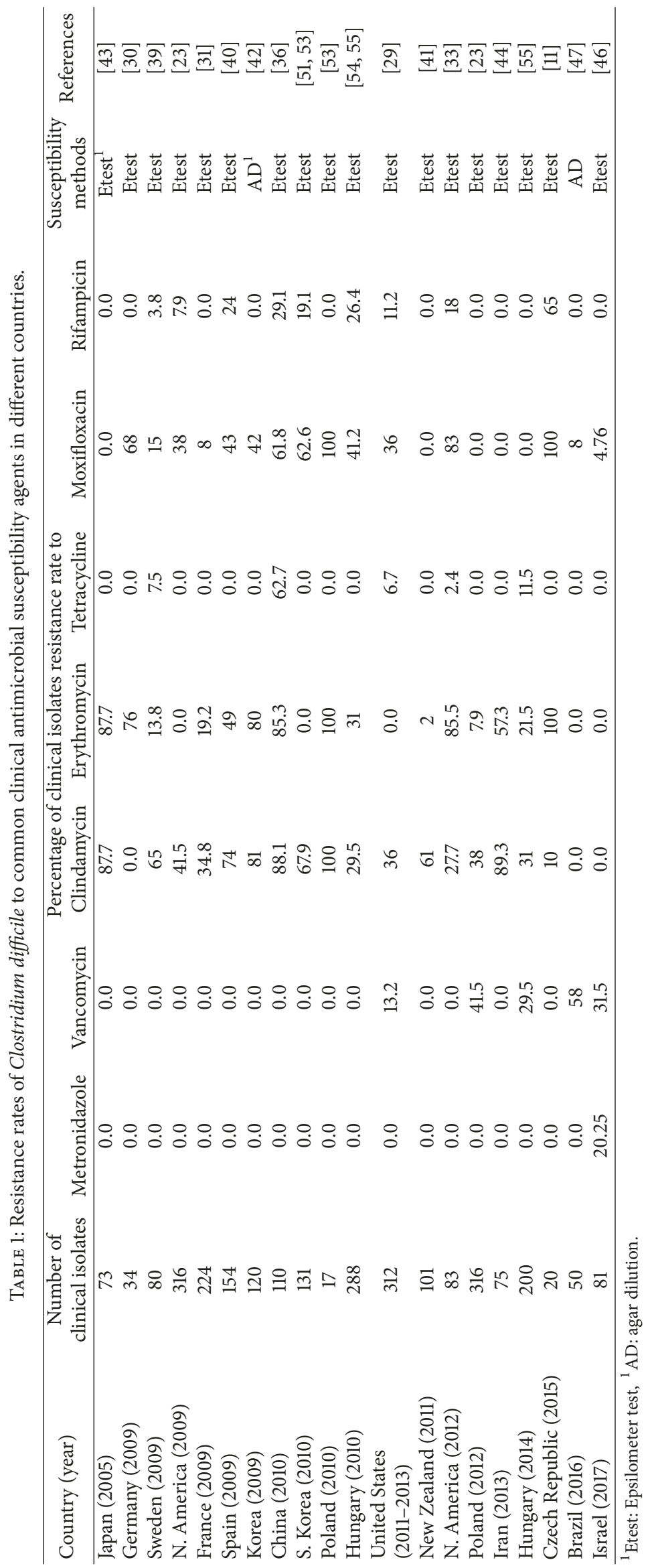


differences between these two organizations that should be highlighted. Both methods have standardized (e.g., metronidazole) susceptibility test of anaerobic bacteria. According to their guidelines, anaerobic bacteria were classified as susceptible if the metronidazole MIC $\leq 8 \mu \mathrm{g} / \mathrm{ml}$; intermediate, if the $\mathrm{MIC}=16 \mu \mathrm{g} / \mathrm{ml}$; or resistant if the $\mathrm{MIC} \geq 32 \mu \mathrm{g} / \mathrm{ml}$, using agar dilution method (CLSI book guidelines, 2012). At least three different methods were used for $C$. difficile test: CLSI agar dilution method and the agar incorporation methods used by [64] and Etest. MIC values are higher with the agar incorporation methods compared with agar dilution methods, and the lowest MICs are achieved using Etest $[65,66]$. Moreover, the susceptibility breakpoint recommended by CLSI and EDCAT differs. For example, the EUCAST breakpoints are susceptibility to metronidazole, $\mathrm{MIC} \leq 2 \mu \mathrm{g} / \mathrm{ml}$, and resistance to metronidazole $\sim \mathrm{MIC} \geq$ $2 \mu \mathrm{g} / \mathrm{ml}$. These issues should be taken into consideration when comparing data from studies or country region utilized different susceptibility testing methods. Perhaps the major reason could be that all the breakpoints are based on serum drug concentrations but that effective antimicrobial therapy of CDI requires bactericidal intracolonic concentrations. Thus, clinical breakpoints are needed to be revised to help in predicting outcome and help to detect resistance mechanisms.

The bactericidal mechanism of metronidazole is not yet fully understood. Perhaps metronidazole metabolites are nonspecifically bound to bacterial DNA, inhibit bacterial DNA synthesis, and break the DNA strand to cause bacterial death. Furthermore, the metronidazole susceptibility and resistance mechanisms of $C$. difficile and other anaerobic bacteria are not yet clear. Researchers speculate that metronidazole may be reduced inside the cell. Increased metronidazole activation blocks bacteria's capacity for DNA repair [67].

3.2. Vancomycin. Vancomycin is the first antibiotic developed to treat moderate to severe CDI $[57,58]$. The vancomycin structure contains a glycosylated hexapeptide chain and aromatic rings cross-linked by aryl ether bonds and exhibits poor absorption in the gastrointestinal tract [68]. To date, only in Poland have researchers reported three strains of $C$. difficile that are resistant to vancomycin, using the disc diffusion method [69]. Two additional methods have been used to detect vancomycin susceptibility: the agar dilution method and the Etest method. According to the European Committee on Antimicrobial Susceptibility Testing (EUCAST), reduced susceptibly to vancomycin is defined as an MIC of $>2 \mu \mathrm{g} / \mathrm{ml}$. Recent studies have found that in Brazil and Israel approximately $58 \%$ and $31.5 \%$ of strains, respectively, are resistant to vancomycin (Table 1) [46, 47].

Vancomycin inhibits the biosynthesis of peptidoglycan by binding to D-alanyl-D-alanine at the end of the bacterial peptidoglycan precursor, which inhibits the synthesis of cell wall peptidoglycans [70]. Enterococcus spp. and Staphylococcus spp. are the most common bacteria with resistance to vancomycin. The reason is the synthesis of D-alanyl-D-lactic acid, which replaces the normal cell wall peptidoglycan end of $\mathrm{D}$-alanyl-D-alanine such that vancomycin is not able to bind the target (VanA, etc.). Another possibility is that synthetic
D-alanyl-D-serine replaces the normal cell wall structure (VanE, etc.). Nevertheless, the mechanism of resistance in $C$. difficile is still unclear.

3.3. Fidaxomicin. In 2011, fidaxomicin was listed in the United States and Europe as a new treatment against CDI [52, 54]. Fidaxomicin acts through the inhibition of RNA polymerase during bacterial transcription. The sequence resulting from PCR amplification displayed a null mutation in the rpoC of the resistant strain [71]. Studies determined that the sequenced laboratory-induced-fidaxomicin-sensitive strains (MIC of 1 to $4 \mu \mathrm{g} / \mathrm{ml}$ ) contained Quot, $\operatorname{rpoB}(\mathrm{K} 1073 \mathrm{H}$, Q1074K, Q1074H, V1143G, and/or V1143D) or rpoC (I10R, R89G, Q781R, and/or D1127E); rpoB and $r p o C$ are the coding genes of RNA polymerase $\beta$ subunit and $\beta^{\prime}$ subunit, respectively [72]. Interestingly, the abovementioned results confirm that target site modifications in the RNA polymerase subunit of $C$. difficile against fidaxomicin are the suggested mode of resistance. In addition, the null mutation in the CD22120 gene that is homologous to the transcriptional regulator MarR family was found in a susceptible experimental strain [72], but the significance of the mutation remains to be further studied.

3.4. Erythromycin and Clindamycin. Erythromycin and clindamycin are members of the macrolide-lincosamide-streptogramin B (MLSB) family of protein synthesis inhibitors. Macrolide-lincomycin-type drugs are currently reported in countries exhibiting high resistance rates [73]. These drugs act on the bacterial ribosome 50S subunit and target the synthesis of bacterial proteins by inhibiting the extension of the peptide chain. A recent study found that clinical pathogens are resistant to erythromycin and clindamycin, mainly through ribosomal target changes or active efflux, while inactivated enzyme production can also cause bacteria to be resistant. The associated ribosomal methylase, encoded by the $\mathrm{ermB}$ gene, can modify ribosomal $23 \mathrm{~S}$ rRNA, leading to high levels of resistance to these drugs [74]. The ermB gene is divided into different classes according to its sequence similarity, and its subtype now includes more than 20 species [75].

C. difficile resistance to erythromycin is encoded by the ermB gene located on the mobilizable conjugative transposon termed Tn5398 [75, 76], and researchers have reported that the $\mathrm{ermB}$ gene is located at other sites [77]. The ermB gene determines the polymorphism of a given region; for example, ermB in Europe determines the genetic structure of E4 and E15, which are the most common. Furthermore, erm genenegative $C$. difficile can also show high levels of erythromycin resistance; however, the mechanism is unknown, particularly in which part of the strain $23 \mathrm{~S}$ rDNA nucleotide substitution $(\mathrm{C} \rightarrow \mathrm{T})$ at position 656 occurs [78].

3.5. Tetracycline. Recent studies have demonstrated that $C$. difficile resistance to tetracycline varies among different countries from $2.4 \%$ to $62.7 \%$ (Table 1) [32, 33, 38, 79-81]. Tetracycline is a rapid bacteriostatic agent that binds specifically to the axon initial segment of the bacterial ribosome 
30 S subunit, preventing aminoacyl-tRNA from binding to ribosomes, thereby inhibiting peptide chain elongation and protein synthesis. The mechanism of resistance to tetracycline by clinical pathogens is mainly associated with tetracycline resistance protein (tetM) and the active efflux system (tet $A$, $\mathrm{B}, \mathrm{C}, \mathrm{D}$, etc.).

C. difficile is resistant to tetracycline, mostly by producing ribosomal protective protein (TetM), usually found on a conjugative Tn916-like element [81-83]. It was found that tetramine-resistant strains of tetracycline-resistant tetracycline were mostly transported by the Tn5397 transposon, whereas tetramine 017 and 078 were mostly located on Tn916like transposons $[84,85]$.

3.6. Fluoroquinolones. Fluoroquinolones belong to a family of broad-spectrum antibiotics and are strongly linked to CDI $[86,87]$. The widespread prevalence of strain 027 may be associated with resistance to fluoroquinolones. Many countries, such as New Zealand, Sweden, China Taiwan, France, and Germany, have $C$. difficile fluoroquinolone resistance rates between $7 \%$ and $40 \%$; some resistance rates even exceed $80 \%$, such as those of strains isolated from a multiinstitutional outbreak in Quebec, Canada (Table 1) [88-91]. Fluoroquinolones act on either bacterial DNA gyrase and/or topoisomerase IV, leading to a cleavage of enzyme-DNA complexes and to inhibition of bacterial DNA synthesis [92].

The resistance mechanism of bacteria to fluoroquinolones is generally caused by two main mechanisms: (1) alteration of the drug target by a mutation in the encoding genes, leading to reduced affinity for the drug; and (2) either an increase in the active efflux of the drug or a decrease in permeability [92]. Previous studies have shown that $C$. difficile's resistance to quinolone is due to changes in DNA gyrase subunit GyrA and/or GyrB [92]. These mutations can be found in the quinolone-resistance-determining region (QRDR) [92]. T82I is the most common site of mutation in GyrA. D71V, T82V, D81N, A83V, A118V, and A118T are the most common mutation sites in GyrB. In addition to these, D426N, D426V, R447K, R447L, S416A, E466K, A503S, S366A, and D501E are also the susceptible sites for mutations in $\operatorname{GyrB}[69,93,94]$.

3.7. Rifamycin Class. Two clinical members of rifamycin drugs are used for the treatment of CDI, rifamycin and rifaximin [95]. In 2009, a study reported that, in the United States and Canada, epidemic strains of $C$. difficile were resistant to RIF (approximately 7.9\%) (Table 1) [23]. A study conducted in Spain reported that RIF resistance was $\sim 24 \%$ (Table 1) [40]. Researchers from Hungary reported that the resistance rate of $C$. difficile was $\sim 11.5 \%-14.9 \%$ from 2008 to 2010 (Table 1) $[54,55]$. In 2010, a study in Poland reported a high rate of resistance of $C$. difficile to RIF of approximately $80 \%$ (Table 1) [53]. In China and South Korea, the resistance rate of $C$. difficile to RIF is quite low compared with that in Europe countries ( $19.8 \%)$, and strains resistant to RIF (MIC $\geq 32 \mu \mathrm{g} / \mathrm{ml}$ ) have also been shown to be resistant to RFX $[36,51]$.

The major resistance mechanism of RIF is specifically associated with a mutation in DNA-dependent RNA polymerase beta subunit (RpoB), and RIF binds to form a stable complex that inhibits polymerase activity and inhibits DNA transcription. C. difficile and other Gram-positive bacteria resistant to RIF are also associated with a point mutation in RpoB. Recent studies have identified eight different RpoBs in $C$. difficile. All eight of the identified mutations involve substitutions between amino acids 488 and 548 . R505K is the most common single substitution, usually leading to high levels of resistance ( $\mathrm{MIC} \geq 32 \mu \mathrm{g} / \mathrm{ml}$ ). By comparison, $\mathrm{H} 502 \mathrm{~N}$ shows a slightly lower MIC $(\mathrm{MIC}<32 \mu \mathrm{g} / \mathrm{ml})$. Double substitution has also been described, such as R505K being combined with $\mathrm{H} 502 \mathrm{~N}$ or R505K being combined with I548M [96, 97].

\section{Conclusion}

The rate of $C$. difficile resistance to antimicrobials is rapidly growing worldwide. CDI has become a major concern for public health officials. Infections caused by $C$. difficile are unique because of their increased incidence as well as the increased use of certain antibiotics. Although some antibiotics are active and can be used to treat infections caused by $C$. difficile, the limitations of using these antibiotics have become a great concern due to increasing resistance in this pathogen. Further investigation is needed to understand the drug resistance mechanism of $C$. difficile, particularly to metronidazole, because it will provide new targets and new ideas for the development of antimicrobial agents and preventing CDI. Additionally, more attention is required at the clinical level regarding the strengthening of $C$. difficile's resistance to avoid the blind use of broad-spectrum antimicrobial drugs, which should decrease the number of occurrences and the spread of drug-resistant C. difficile infections.

\section{Abbreviations

$\begin{array}{ll}\text { C. difficile: } & \text { Clostridium difficile } \\ \text { CDI: } & \text { C. difficile infection } \\ \text { RT: } & \text { Ribotype. }\end{array}$

\section{Conflicts of Interest}

The author declares no potential conflicts of interest with respect to the research, funds, authorship, and competing interests.

\section{Acknowledgments}

The author would like to thank Deanship of Scientific Research at Majmaah University for supporting this work under Project no. 37/99.

\section{References}

[1] C. T. Evans and N. Safdar, "Current trends in the epidemiology and outcomes of Clostridium difficile infection," Clinical Infectious Diseases, vol. 60, pp. S66-S71, 2015.

[2] F. C. Lessa, Y. Mu, W. M. Bamberg et al., "Burden of Clostridium difficile infection in the United States," The New England Journal of Medicine, vol. 372, no. 9, pp. 825-834, 2015. 
[3] Z. Peng, D. Jin, H. B. Kim et al., "Update on antimicrobial resistance in Clostridium difficile: Resistance mechanisms and antimicrobial susceptibility testing," Journal of Clinical Microbiology, vol. 55, no. 7, pp. 1998-2008, 2017.

[4] C. O’Donoghuea and L. Kyne, "Update on Clostridium difficile infection," Current Opinion in Gastroenterology, vol. 27, no. 1, pp. 38-47, 2011.

[5] M. Rupnik, M. H. Wilcox, and D. N. Gerding, "Clostridium difficile infection: new developments in epidemiology and pathogenesis," Nature Reviews Microbiology, vol. 7, no. 7, pp. 526-536, 2009.

[6] S. H. Cohen, D. N. Gerding, S. Johnson et al., "Clinical practice guidelines for Clostridium difficile infection in adults: 2010 update by the society for healthcare epidemiology of America (SHEA) and the infectious diseases society of America (IDSA)," Infection Control and Hospital Epidemiology, vol. 31, no. 5, pp. 431-455, 2010.

[7] D. A. Collins, P. M. Hawkey, and T. V. Riley, "Epidemiology of Clostridium difficile infection in Asia," Antimicrobial Resistance and Infection Control, vol. 2, no. 1, article no. 21, 2013.

[8] L. C. McDonald, G. E. Killgore, A. Thompson et al., "An epidemic, toxin gene-variant strain of Clostridium difficile," The New England Journal of Medicine, vol. 353, no. 23, pp. 2433-2441, 2005.

[9] C. A. Muto, M. K. Blank, J. W. Marsh et al., "Control of an outbreak of infection with the hypervirulent Clostridium difficile BI strain in a university hospital using a comprehensive "bundle" approach," Clinical Infectious Diseases, vol. 45, no. 10, pp. 1266-1273, 2007.

[10] A. C. Clements, R. J. S. Magalhães, A. J. Tatem, D. L. Paterson, and T. V. Riley, "Clostridium difficile PCR ribotype 027: assessing the risks of further worldwide spread," The Lancet Infectious Diseases, vol. 10, no. 6, pp. 395-404, 2010.

[11] M. Krutova, J. Matejkova, J. Tkadlec, and O. Nyc, "Antibiotic profiling of Clostridium difficile ribotype 176 - A multidrug resistant relative to C. difficile ribotype 027," Anaerobe, vol. 36, pp. 88-90, 2015.

[12] J. H. Kwon, M. A. Olsen, and E. R. Dubberke, "The morbidity, mortality, and costs associated with Clostridium difficile infection," Infectious Disease Clinics of North America, vol. 29, no. 1, pp. 123-134, 2015.

[13] S. M. McGlone, R. R. Bailey, S. M. Zimmer et al., "The economic burden of Clostridium difficile," Clinical Microbiology and Infection, vol. 18, no. 3, pp. 282-289, 2012.

[14] A. Goorhuis, D. Bakker, J. Corver et al., "Emergence of Clostridium difficile infection due to a new hypervirulent strain, polymerase chain reaction ribotype 078," Clinical Infectious Diseases, vol. 47, no. 9, pp. 1162-1170, 2008.

[15] A. Goorhuis, T. Van Der Kooi, N. Vaessen et al., "Spread and epidemiology of Clostridium difficile polymerase chain reaction ribotype 027/toxinotype III in The Netherlands," Clinical Infectious Diseases, vol. 45, no. 6, pp. 695-703, 2007.

[16] M. P. Bauer, D. W. Notermans, B. H. B. Van Benthem et al., "Clostridium difficile infection in Europe: a hospital-based survey," The Lancet, vol. 377, no. 9759, pp. 63-73, 2011.

[17] B. M. Limbago, C. M. Long, A. D. Thompson et al., "Clostridium difficile strains from community-associated infections," Journal of Clinical Microbiology, vol. 47, no. 9, pp. 3004-3007, 2009.

[18] K. Keel, J. S. Brazier, K. W. Post, S. Weese, and J. G. Songer, "Prevalence of PCR ribotypes among Clostridium difficile isolates from pigs, calves, and other species," Journal of Clinical Microbiology, vol. 45, no. 6, pp. 1963-1964, 2007.
[19] X. Sun and S. A. Hirota, "The roles of host and pathogen factors and the innate immune response in the pathogenesis of Clostridium difficile infection," Molecular Immunology, vol. 63, no. 2, pp. 193-202, 2015.

[20] C. P. Kelly and J. T. LaMont, "Clostridium difficile-More difficult than ever," The New England Journal of Medicine, vol. 359, no. 18, pp. 1932-1940, 2008.

[21] D. A. Leffler and J. T. Lamont, "Clostridium difficile infection," The New England Journal of Medicine, vol. 372, no. 16, pp. 15391548, 2015.

[22] H. Huang, S. Wu, M. Wang et al., "Molecular and clinical characteristics of Clostridium difficile infection in a university hospital in Shanghai, China," Clinical Infectious Diseases, vol. 47, no. 12, pp. 1606-1608, 2008.

[23] F. C. Tenover, I. A. Tickler, and D. H. Persing, "Antimicrobialresistant strains of Clostridium difficile from North America," Antimicrobial Agents and Chemotherapy, vol. 56, no. 6, pp. 2929-2932, 2012.

[24] P. Obuch-Woszczatyński, D. Lachowicz, A. Schneider et al., "Occurrence of Clostridium difficile PCR-ribotype 027 and it's closely related PCR-ribotype 176 in hospitals in Poland in 2008-2010," Anaerobe, vol. 28, pp. 13-17, 2014.

[25] N. Bagdasarian, K. Rao, and P. N. Malani, "Diagnosis and treatment of Clostridium difficile in adults: A systematic review," Journal of the American Medical Association, vol. 313, no. 4, pp. 398-408, 2015.

[26] D. N. Gerding, T. M. File, and L. C. McDonald, "Diagnosis and treatment of Clostridium difficile infection," Infectious Diseases in Clinical Practice, vol. 24, no. 1, pp. 3-10, 2016.

[27] R. C. Owens Jr., C. J. Donskey, R. P. Gaynes, V. G. Loo, and C. A. Muto, "Antimicrobial-associated risk factors for Clostridium difficile infection," Clinical Infectious Diseases, vol. 46, supplement 1, pp. S19-S31, 2008.

[28] A. Ofosu, "Clostridium difficile infection: A review of current and emerging therapies," Annals of Gastroenterology, vol. 29, no. 2, pp. 147-154, 2016.

[29] I. A. Tickler, R. V. Goering, J. D. Whitmore, A. N. W. Lynn, D. H. Persing, and F. C. Tenover, "Strain types and antimicrobial resistance patterns of Clostridium difficile isolates from the United States, 2011 to 2013," Antimicrobial Agents and Chemotherapy, vol. 58, no. 7, pp. 4214-4218, 2014.

[30] M. Reil, M. P. M. Hensgens, E. J. Kuijper et al., "Seasonality of Clostridium difficile infections in Southern Germany," Epidemiology and Infection, vol. 140, no. 10, pp. 1787-1793, 2012.

[31] C. Eckert, B. Coignard, M. Hebert et al., "Clinical and microbiological features of Clostridium difficile infections in France: The ICD-RAISIN 2009 national survey," Médecine et Maladies Infectieuses, vol. 43, no. 2, pp. 67-74, 2013.

[32] Y. Zhou, C.-A. D. Burnham, T. Hink et al., "Phenotypic and genotypic analysis of Clostridium difficile isolates: a singlecenter study," Journal of Clinical Microbiology, vol. 52, no. 12, pp. 4260-4266, 2014.

[33] D. Lachowicz, H. Pituch, and P. Obuch-Woszczatyński, "Antimicrobial susceptibility patterns of Clostridium difficile strains belonging to different polymerase chain reaction ribotypes isolated in Poland in 2012," Anaerobe, vol. 31, pp. 37-41, 2015.

[34] T. Peláez, L. Alcalá, R. Alonso et al., "In vitro activity of ramoplanin against Clostridium difficile, including strains with reduced susceptibility to vancomycin or with resistance to metronidazole," Antimicrobial Agents and Chemotherapy, vol. 49, no. 3, pp. 1157-1159, 2005. 
[35] C. M. Surawicz, L. J. Brandt, D. G. Binion et al., "Guidelines for diagnosis, treatment, and prevention of Clostridium difficile infections," American Journal of Gastroenterology, vol. 108, no. 4, pp. 478-498, 2013.

[36] H. Huang, A. Weintraub, H. Fang, S. Wu, Y. Zhang, and C. E. Nord, "Antimicrobial susceptibility and heteroresistance in Chinese Clostridium difficile strains," Anaerobe, vol. 16, no. 6, pp. 633-635, 2010.

[37] E. Reigadas, L. Alcalá, M. Marín et al., "In vitro activity of surotomycin against contemporary clinical isolates of toxigenic Clostridium difficilestrains obtained in Spain," Journal of Antimicrobial Chemotherapy, vol. 71, no. 11, Article ID dkw267, pp. 3319-3319, 2016.

[38] K. N. Norman, H. M. Scott, R. B. Harvey, B. Norby, and M. E. Hume, "Comparison of antimicrobial susceptibility among Clostridium difficile isolated from an integrated human and swine population in Texas," Foodborne Pathogens and Disease, vol. 11, no. 4, pp. 257-264, 2014.

[39] H. Huang, H. Fang, A. Weintraub, and C. E. Nord, "Distinct ribotypes and rates of antimicrobial drug resistance in Clostridium difficile from Shanghai and Stockholm," Clinical Microbiology and Infection, vol. 15, no. 12, pp. 1170-1173, 2009.

[40] D. Rodríguez-Pardo, B. Almirante, R. M. Bartolomé et al., "Epidemiology of Clostridium difficile infection and risk factors for unfavorable clinical outcomes: Results of a hospital-based study in Barcelona, Spain," Journal of Clinical Microbiology, vol. 51, no. 5, pp. 1465-1473, 2013.

[41] S. Roberts, H. Heffernan, N. A. Anbuky et al., "Molecular epidemiology and susceptibility profiles of Clostridium difficile in New Zealand, 2009," The New Zealand Medical Journal, vol. 124, no. 1332, pp. 45-51, 2011.

[42] J.-H. Lee, Y. Lee, K. Lee, T. V. Riley, and H. Kim, “The changes of PCR ribotype and antimicrobial resistance of Clostridium difficile in a tertiary care hospital over 10 years," Journal of Medical Microbiology, vol. 63, no. 6, pp. 819-823, 2014.

[43] K. Oka, T. Osaki, T. Hanawa et al., "Molecular and microbiological characterization of Clostridium difficile isolates from single, relapse, and reinfection cases," Journal of Clinical Microbiology, vol. 50, no. 3, pp. 915-921, 2012.

[44] M. Goudarzi, H. Goudarzi, M. Alebouyeh et al., "Antimicrobial susceptibility of Clostridium difficile clinical isolates in Iran," Iranian Red Crescent Medical Journal, vol. 15, no. 8, pp. 704-711, 2013.

[45] J. A. Karlowsky, G. G. Zhanel, G. W. Hammond et al., "Multidrug-resistant North American pulsotype 2 Clostridium difficile was the predominant toxigenic hospital-acquired strain in the province of Manitoba, Canada, in 2006-2007," Journal of Medical Microbiology, vol. 61, no. 5, pp. 693-700, 2012.

[46] L. Tkhawkho, O. Nitzan, N. Pastukh, D. Brodsky, K. Jackson, and A. Peretz, "Antimicrobial susceptibility of Clostridium difficile isolates in Israel," Journal of Global Antimicrobial Resistance, vol. 10, pp. 161-164, 2017.

[47] E. G. Fraga, A. C. Nicodemo, and J. L. M. Sampaio, "Antimicrobial susceptibility of Brazilian Clostridium difficile strains determined by agar dilution and disk diffusion," The Brazilian Journal of Infectious Diseases, vol. 20, no. 5, pp. 476-481, 2016.

[48] M. Wikler, Clinical and Laboratory Standards Institute. Methods for dilution antimicrobial susceptibility tests for bacteria that grow aerobically; approved standard. 8th edition, 2015.

[49] Clinical and Laboratory Standards InstituteMethods for antimicrobial susceptibility testing of anaerobic bacteria; approved standard. 8th edition, 2012.
[50] S. Waslawski, E. S. Lo, S. A. Ewing et al., "Clostridium difficile ribotype diversity at six health care institutions in the United States," Journal of Clinical Microbiology, vol. 51, no. 6, pp. 19381941, 2013.

[51] J. Kim, J. O. Kang, H. Pai, and T. Y. Choi, "Association between PCR ribotypes and antimicrobial susceptibility among Clostridium difficile isolates from healthcare-associated infections in South Korea," International Journal of Antimicrobial Agents, vol. 40, no. 1, pp. 24-29, 2012.

[52] P. Spigaglia, "Recent advances in the understanding of antibiotic resistance in Clostridium difficile infection," Therapeutic Advances in Infectious Disease, vol. 3, no. 1, pp. 23-42, 2015.

[53] P. Obuch-Woszczatyński, G. Dubiel, C. Harmanus et al., "Emergence of Clostridium difficile infection in tuberculosis patients due to a highly rifampicin-resistant PCR ribotype 046 clone in Poland," European Journal of Clinical Microbiology \& Infectious Diseases, vol. 32, no. 8, pp. 1027-1030, 2013.

[54] Z. Eitel, G. Terhes, J. Sóki, E. Nagy, and E. Urbán, "Investigation of the MICs of fidaxomicin and other antibiotics against Hungarian Clostridium difficile isolates," Anaerobe, vol. 31, pp. 47-49, 2015.

[55] G. Terhes, A. Maruyama, K. Latkóczy et al., "Invitro antibiotic susceptibility profile of Clostridium difficile excluding PCR ribotype 027 outbreak strain in Hungary," Anaerobe, vol. 30, pp. 41-44, 2014.

[56] P. Goldman, "The development of 5-nitroimidazoles for the treatment and prophylaxis of anaerobic bacterial infections," Journal of Antimicrobial Chemotherapy, vol. 10, pp. 23-33, 1982.

[57] S. B. Debast, M. P. Bauer, E. J. Kuijper et al., "European society of clinical microbiology and infectious diseases: update of the treatment guidance document for Clostridium difficile infection," Clinical Microbiology and Infection, vol. 20, no. 2, pp. 1-26, 2014.

[58] A. M. Jarrad, T. Karoli, M. A. T. Blaskovich, D. Lyras, and M. A. Cooper, "Clostridium difficile drug pipeline: challenges in discovery and development of new agents," Journal of Medicinal Chemistry, vol. 58, no. 13, pp. 5164-5185, 2015.

[59] T. Pelaez, R. Sanchez, and R. Blazquez, "Metronidazole resistance in Clostridium difficile: a new emerging problem," in Proceedings of the Program and Abstracts of the 34th Interscience Conference on Antimicrobial Agents and Chemotherapy (ICAAC '98), 1998.

[60] T. Pelaez, E. Cercenado, L. Alcala et al., "Metronidazole resistance in Clostridium difficile is heterogeneous," Journal of Clinical Microbiology, vol. 46, no. 9, pp. 3028-3032, 2008.

[61] S. D. Baines, R. O'Connor, J. Freeman et al., "Emergence of reduced susceptibility to metronidazole in Clostridium difficile," Journal of Antimicrobial Chemotherapy, vol. 62, no. 5, pp. 10461052, 2008.

[62] G. Kahlmeter, D. F. J. Brown, F. W. Goldstein et al., "European committee on antimicrobial susceptibility testing (EUCAST) technical notes on antimicrobial susceptibility testing," Clinical Microbiology and Infection, vol. 12, no. 6, pp. 501-503, 2006.

[63] M. P. Bauer, E. J. Kuijper, and J. T. Van Dissel, "European society of clinical microbiology and infectious diseases (ESCMID): Treatment guidance document for Clostridium difficile infection (CDI)," Clinical Microbiology and Infection, vol. 15, no. 12, pp. 1067-1079, 2009.

[64] J. Freeman, J. Stott, S. D. Baines, W. N. Fawley, and M. H. Wilcox, "Surveillance for resistance to metronidazole and vancomycin in genotypically distinct and UK epidemic Clostridium difficile 
isolates in a large teaching hospital," Journal of Antimicrobial Chemotherapy, vol. 56, no. 5, pp. 988-989, 2005.

[65] I. Poilane, P. Cruaud, J. C. Torlotin, and A. Collignon, "Comparison of the E test to the reference agar dilution method for antiobiotic susceptibility testing of Clostridium difficile," Clinical Microbiology and Infection, vol. 6, no. 3, pp. 154-156, 2000.

[66] I. Moura, P. Spigaglia, F. Barbanti, and P. Mastrantonio, "Analysis of metronidazole susceptibility in different Clostridium difficile PCR ribotypes," Journal of Antimicrobial Chemotherapy, vol. 68, no. 2, pp. 362-365, 2013.

[67] S. Löfmark, C. Edlund, and C. E. Nord, "Metronidazole is still the drug of choice for treatment of anaerobic infections," Clinical Infectious Diseases, vol. 50, no. 1, pp. S16-S23, 2010.

[68] X. Yu and D. Sun, "Macrocyclic drugs and synthetic methodologies toward macrocycles," Molecules, vol. 18, no. 6, pp. 62306268, 2013.

[69] A. Dworczyński, B. Sokół, and F. Meisel-Mikołajczyk, "Antibiotic resistance of Clostridium difficile isolates," Cytobios, vol. 65, pp. 149-153, 1990.

[70] H. R. Perkins and M. Nieto, "The chemical basis for the action of the vancomycin group of antibiotics," Annals of the New York Academy of Sciences, vol. 235, no. 1, pp. 348-363, 1974.

[71] E. J. C. Goldstein, D. M. Citron, P. Sears, F. Babakhani, S. P. Sambol, and D. N. Gerding, "Comparative susceptibilities to fidaxomicin (OPT-80) of isolates collected at baseline, recurrence, and failure from patients in two phase III trials of fidaxomicin against Clostridium difficile infection," Antimicrobial Agents and Chemotherapy, vol. 55, no. 11, pp. 5194-5199, 2011.

[72] J. A. Leeds, M. Sachdeva, S. Mullin, S. Whitney Barnes, and A. Ruzin, "In vitro selection, via serial passage, of Clostridium difficile mutants with reduced susceptibility to fidaxomicin or vancomycin," Journal of Antimicrobial Chemotherapy, vol. 69, no. 1, Article ID dkt302, pp. 41-44, 2014.

[73] J. G. Bartlett, A. B. Onderdonk, R. L. Cisneros, and etal., "Clindamycin-associated colitis due to a toxin-producing species of Clostridium in hamsters," The Journal of Infectious Diseases, vol. 136, no. 5, pp. 701-705, 1977.

[74] R. Leclercq, "Mechanisms of resistance to macrolides and lincosamides: Nature of the resistance elements and their clinical implications," Clinical Infectious Diseases, vol. 34, no. 4, pp. 482492, 2002.

[75] H. Huang, A. Weintraub, H. Fang, and C. E. Nord, "Antimicrobial resistance in Clostridium difficile," International Journal of Antimicrobial Agents, vol. 34, no. 6, pp. 516-522, 2009.

[76] K. A. Farrow, D. Lyras, and J. I. Rood, "Genomic analysis of the erythromycin resistance element Tn5398 from Clostridium difficile," Microbiology, vol. 147, no. 10, pp. 2717-2728, 2001.

[77] P. Spigaglia, F. Barbanti, and P. Mastrantonio, "Detection of a genetic linkage between genes coding for resistance to tetracycline and erythromycin in Clostridium difficile," Microbial Drug Resistance, vol. 13, no. 2, pp. 90-95, 2007.

[78] C. Schmidt, B. Löffler, and G. Ackermann, "Antimicrobial phenotypes and molecular basis in clinical strains of Clostridium difficile," Diagnostic Microbiology and Infectious Disease, vol. 59, no. 1, pp. 1-5, 2007.

[79] D. Dong, L. Zhang, X. Chen et al., "Antimicrobial susceptibility and resistance mechanisms of clinical Clostridium difficile from a Chinese tertiary hospital," International Journal of Antimicrobial Agents, vol. 41, no. 1, pp. 80-84, 2013.

[80] T. Pirš, J. Avberšek, I. Zdovc et al., "Antimicrobial susceptibility of animal and human isolates of Clostridium difficile by broth microdilution," Journal of Medical Microbiology, vol. 62, pp. 1478-1485, 2013.

[81] M. Linkevicius, L. Sandegren, and D. I. Andersson, "Potential of tetracycline resistance proteins to evolve tigecycline resistance," Antimicrobial Agents and Chemotherapy, vol. 60, no. 2, pp. 789796, 2016.

[82] P. Spigaglia, F. Barbanti, and P. Mastrantonio, "New variants of the tet $(\mathrm{M})$ gene in Clostridium difficile clinical isolates harbouring Tn916-like elements," Journal of Antimicrobial Chemotherapy, vol. 57, no. 6, pp. 1205-1209, 2006.

[83] P. Mullany, M. Wilks, I. Lamb, C. Clayton, B. Wren, and S. Tabaqchali, "Genetic analysis of a tetracycline resistance element from Clostridium difficile and its conjugal transfer to and from Bacillus subtilis," Journal of General Microbiology, vol. 136, no. 7, pp. 1343-1349, 1990.

[84] M. Sebaihia, B. W. Wren, P. Mullany et al., "The multidrugresistant human pathogen Clostridium difficile has a highly mobile, mosaic genome," Nature Genetics, vol. 38, no. 7, pp. 779786, 2006.

[85] D. Dong, X. Chen, C. Jiang et al., "Genetic analysis of Tn916-like elements conferring tetracycline resistance in clinical isolates of Clostridium difficile," International Journal of Antimicrobial Agents, vol. 43, no. 1, pp. 73-77, 2014.

[86] C. A. Muto, M. Pokrywka, K. Shutt et al., "A large outbreak of Clostridium difficile-associated disease with an unexpected proportion of deaths and colectomies at a teaching hospital following increased fluoroquinolone use," Infection Control and Hospital Epidemiology, vol. 26, no. 3, pp. 273-280, 2005.

[87] J. Pépin, N. Saheb, M.-A. Coulombe et al., "Emergence of fluoroquinolones as the predominant risk factor for Clostridium difficile-associated diarrhea: a cohort study during an epidemic in Quebec," Clinical Infectious Diseases, vol. 41, no. 9, pp. 12541260, 2005.

[88] G. Ackermann, A. Degner, S. H. Cohen, J. Silva Jr., and A. C. Rodloff, "Prevalence and association of macrolide-lincosamidestreptogramin B (MLSB) resistance with resistance to moxifloxacin in Clostridium difficile," Journal of Antimicrobial Chemotherapy, vol. 51, no. 3, pp. 599-603, 2003.

[89] A.-M. Bourgault, F. Lamothe, V. G. Loo, and L. Poirier, "In vitro susceptibility of Clostridium difficile clinical isolates from a multi-institutional outbreak in southern Québec, Canada," Antimicrobial Agents and Chemotherapy, vol. 50, no. 10, pp. 3473-3475, 2006.

[90] F. Barbut, P. Mastrantonio, M. Delmée et al., "Prospective study of Clostridium difficile infections in Europe with phenotypic and genotypic characterisation of the isolates," Clinical Microbiology and Infection, vol. 13, no. 11, pp. 1048-1057, 2007.

[91] L. Dridi, J. Tankovic, B. Burghoffer, F. Barbut, and J.-C. Petit, "gyrA and gyrB mutations are implicated in cross-resistance to ciprofloxacin and moxifloxacin in Clostridium difficile," Antimicrobial Agents and Chemotherapy, vol. 46, no. 11, pp. 3418-3421, 2002.

[92] H. Oh and C. Edlund, "Mechanism of quinolone resistance in anaerobic bacteria," Clinical Microbiology and Infection, vol. 9, no. 6, pp. 512-517, 2003.

[93] G. Ackermann, Y. J. Tang, R. Kueper et al., "Resistance to moxifloxacin in toxigenic Clostridium difficile isolates is associated with mutations in gyrA," Antimicrobial Agents and Chemotherapy, vol. 45, no. 8, pp. 2348-2353, 2001.

[94] D. Drudy, T. Quinn, R. O’Mahony, L. Kyne, P. Ó'Gaora, and S. Fanning, "High-level resistance to moxifloxacin and 
gatifloxacin associated with a novel mutation in gyrB in toxinA-negative, toxin-B-positive Clostridium difficile," Journal of Antimicrobial Chemotherapy, vol. 58, no. 6, pp. 1264-1267, 2006.

[95] K. W. Garey, M. Salazar, D. Shah, R. Rodrigue, and H. L. DuPont, "Rifamycin antibiotics for treatment of Clostridium difficile-associated diarrhea," Annals of Pharmacotherapy, vol. 42, no. 6, pp. 827-835, 2008.

[96] S. R. Curry, J. W. Marsh, K. A. Shutt et al., "High frequency of rifampin resistance identified in an epidemic Clostridium difficile clone from a large teaching hospital," Clinical Infectious Diseases, vol. 48, no. 4, pp. 425-429, 2009.

[97] J. R. O'Connor, M. A. Galang, S. P. Sambol et al., "Rifampin and rifaximin resistance in clinical isolates of Clostridium difficile," Antimicrobial Agents and Chemotherapy, vol. 52, no. 8, pp. 28132817, 2008. 


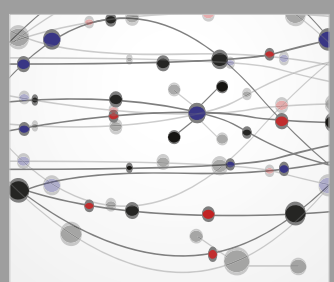

The Scientific World Journal
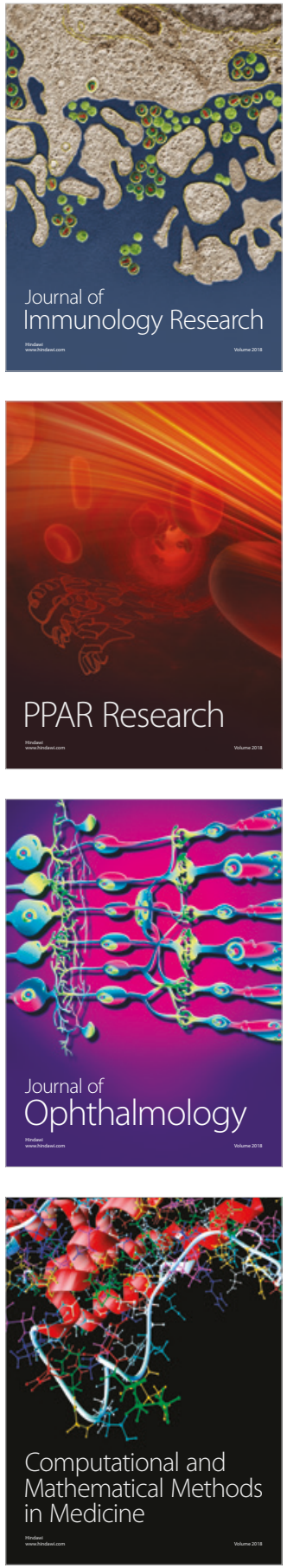

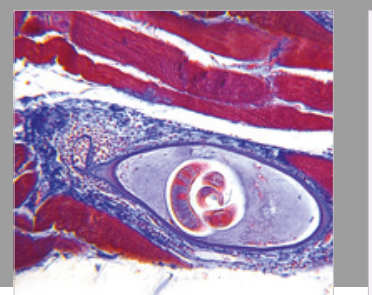

Gastroenterology Research and Practice

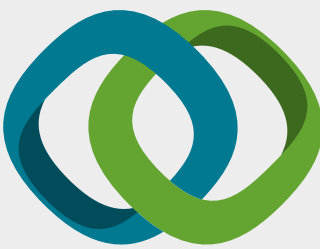

\section{Hindawi}

Submit your manuscripts at

www.hindawi.com
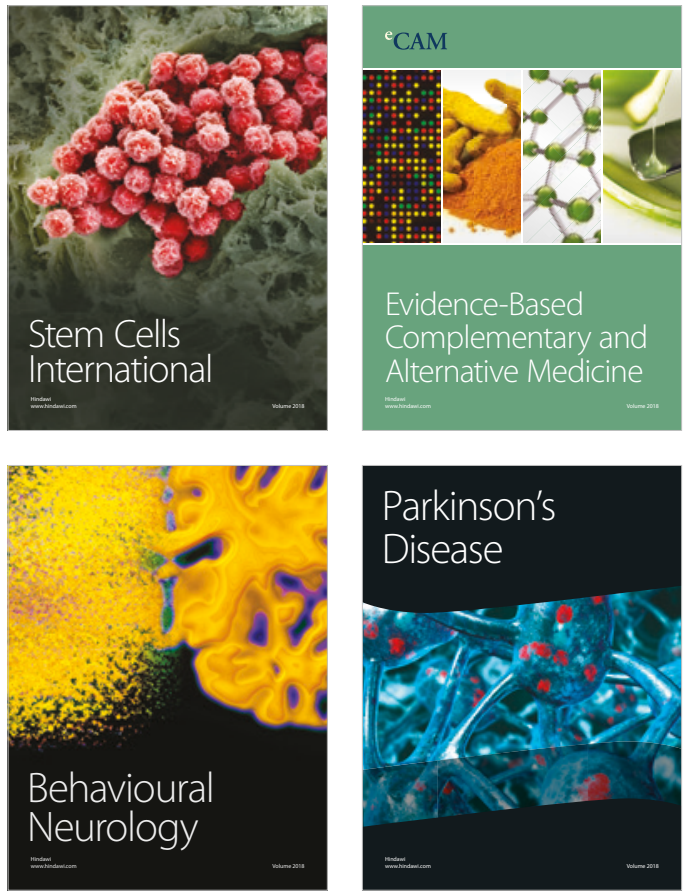

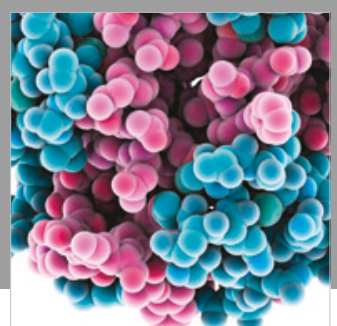

ournal of

Diabetes Research

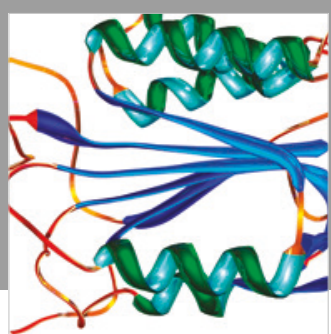

Disease Markers
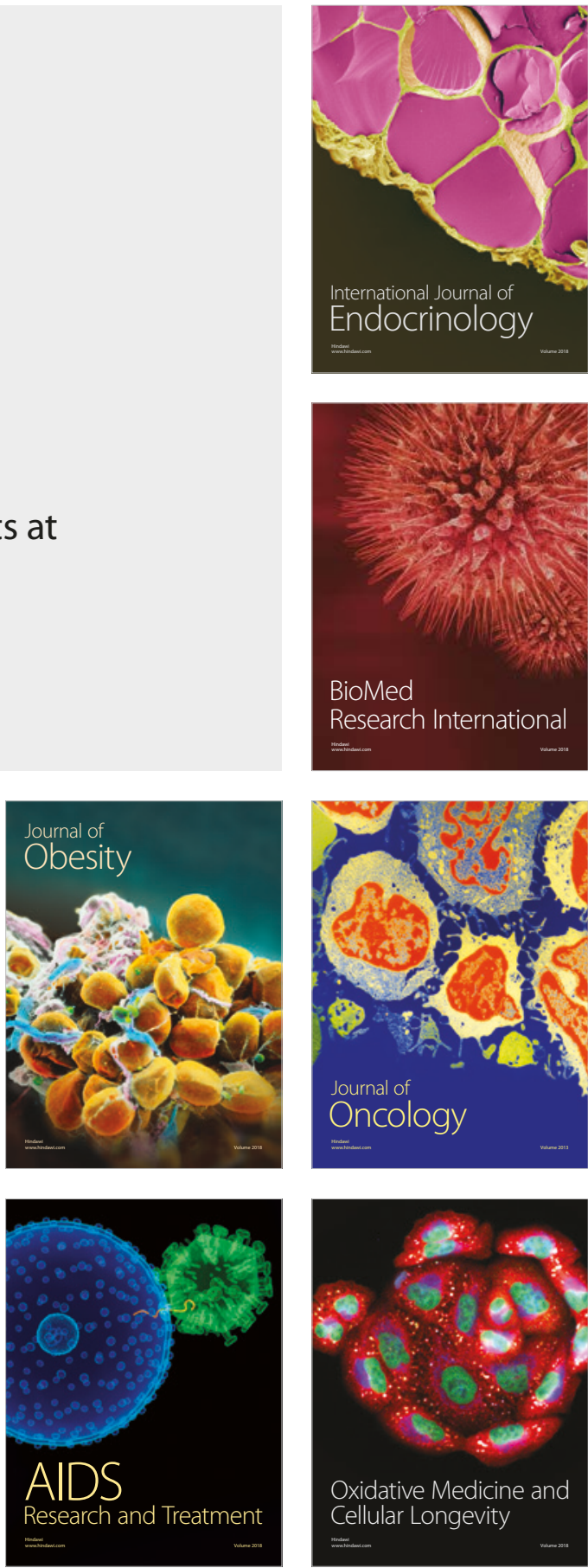